\title{
Análise das concepções de formadores de professores de Química acerca da inclusão de alunos com deficiência no ensino superior
}

\author{
José Gonçalves Teixeira Júnior ${ }^{1}$ \\ Nayara Costa Souza ${ }^{2}$
}

\begin{abstract}
RESUMO
Este trabalho tem como objetivo investigar as concepções de formadores de professores de Química sobre as possibilidades e potenciais dificuldades para ensinar conceitos químicos para licenciandos com deficiências. Mais do que um diagnóstico, compreende-se que as concepções dos formadores de professores acerca da inclusão influenciam também, as concepções dos futuros professores de Química. Para isso, os formadores de uma instituição de ensino superior foram entrevistados, a fim de levá-los a refletir sobre suas metodologias, as necessidades de adaptação, assim como as possíveis dificuldades em lidar com esses alunos. Os resultados apontaram que, embora alguns dos docentes tenham se mostrado receptivos às possibilidades da educação de alunos com necessidades educacionais especiais, nenhum deles sente-se preparado para atuar na diversidade.
\end{abstract}

PALAVRAS-CHAVE: Educação inclusiva. Formação de professores de Química. Concepção de professores.

\section{Analysis of the conceptions of teacher trainers of Chemistry on the inclusion of students with disabilities in higher education}

\begin{abstract}
This work aims to investigate the conceptions of chemistry teacher trainers about the possibilities and potential difficulties to teach chemical
\end{abstract}

\footnotetext{
${ }^{1}$ Doutor em Química. Docente na Universidade Federal de Uberlândia, Ituiutaba, MG. E-mail: goncalves@ufu.br.

${ }^{2}$ Licenciatura em Química. Universidade Federal de Uberlândia, Ituiutaba, MG. E-mail: nayara_cs@ hotmail.com.
} 
concepts for graduates with disabilities. More than a diagnosis, it is understood that teachers' conceptions of inclusion also influence the conceptions of future chemistry teachers. To that end, the trainers of a higher education institution were interviewed to get them to reflect on their methodologies, the needs of adaptation, as well as the possible difficulties in dealing with these students. The results pointed out that although some of the teachers have been receptive to the possibilities of educating students with special educational needs, none of them feel prepared to act in diversity.

KEYWORDS: Inclusive education. Teacher training in chemistry.

Teacher conception.

\section{Introdução}

Em relação à educação inclusiva existem vários documentos oficiais que asseguram um atendimento especializado para alunos com necessidades especiais que utilizam do ensino regular e o aprimoramento dos sistemas educacionais a fim de se tornarem aptos a incluírem todas as crianças, independentemente de suas limitações físicas ou intelectuais (BRASIL, 2001, 2011b, 2012). O objetivo principal dessas legislações é "prevenir e eliminar todas as formas de discriminação contra as pessoas portadoras de deficiência e propiciar a sua plena integração à sociedade" (BRASIL, 2011b), determinando como um dever do estado o atendimento educacional especializado a pessoas com necessidades educativas especiais, preferencialmente na rede regular de ensino. Da mesma forma, garante "professores com especialização adequada em nível médio ou superior, para atendimento especializado, bem como professores do ensino regular capacitados para a integração desses educandos nas classes comuns" (BRASIL, 1996).

Nesta perspectiva, percebe-se uma contradição: de um lado a legislação brasileira que prioriza a inclusão dos alunos com deficiências na rede regular 
de ensino, e do outro lado, o professor que recebe estes alunos e não se sente preparado para atuar nestas classes. Com a ampliação do acesso destes estudantes à educação básica, verificou-se nos últimos anos, que o ingresso de alunos com necessidades educacionais especiais no ensino superior aumentou. Entretanto, Pacheco e Costas (2006) afirmam que as iniciativas para proporcionar acesso, permanência e apoio psicopedagógico para estes alunos nas instituições de ensino superior são, na maioria das vezes, isoladas e insuficientes.

Algumas instituições de ensino superior, como a Universidade de Brasília (UnB), a Universidade Federal de Goiás (UFG), e a Universidade Federal de Uberlândia (UFU) têm recebido alunos com necessidades educacionais especiais para cursar Licenciatura em Química. Desse cenário, é que surgiu o interesse em investigar as concepções dos professores que atuam em curso de Licenciatura em Química sobre a possibilidade de terem alunos com necessidades educacionais especiais. Quais dificuldades os professores do ensino superior poderiam enfrentar ao ensinar Química para um aluno com deficiência auditiva? Eles têm formação em Libras? E o trabalho com alunos com deficiências visuais? Os professores têm conhecimento sobre as metodologias e as possibilidades de adaptação? E o trabalho com alunos com outras necessidades especiais, os professores se sentem preparados? É possível ensinar os conteúdos propostos e desenvolver as habilidades necessárias para a formação de Licenciandos no curso de Química?

O interesse por analisar questões relacionadas à inclusão surgiu a partir da atuação de um dos autores como professor de em curso preparatório para o vestibular, ainda durante a formação inicial, em sala de aula, na qual havia dois alunos com necessidades especiais, um com deficiência auditiva e outro com dislexia. Durante as aulas, era possível observar que os alunos com deficiências apresentavam dificuldades de aprendizagem frente ao conteúdo ensinado. Além disso, a partir dessa observação, foi possível identificar alguns aspectos que o professor de Química enfrentou na sala de aula relacionados à 
presença de alunos com deficiência, tais como: falta ou o desconhecimento de metodologias voltadas para a inclusão, desconhecimento da simbologia Química para a Língua Brasileira de Sinais (Libras) e desinteresse dos alunos com necessidades especiais em relação às aulas.

Camargo e Nardi (2007, p. 380) afirmam que "não se discute nos cursos de licenciatura das universidades brasileiras problemas ligados à relação entre educação e alunos com deficiências". A partir da rememoração da experiência como Licenciando(a), de um(a) dos(as) autores(as) desse artigo, durante a formação inicial em Química, a mesma identificou que a inclusão somente foi abordada em dois momentos do curso: nas aulas da disciplina de Libras e numa atividade realizada durante a disciplina de Instrumentação para o Ensino de Química II, quando foi solicitado pelo professor da disciplina que um experimento fosse repensado para a inclusão de alunos com deficiências visuais. Nessas aulas de Libras, a maior parte da simbologia estudada referia-se à comunicação geral com o aluno com deficiência auditiva e não com a utilização de terminologias específicas para o ensino de Química. Esse cenário vivido associado poderia ser a causa para à dificuldade de lidar com alunos com deficiência, durante a prática docente, ainda na condição de licencianda, nas aulas que ministrava no curso preparatório para o vestibular.

Assim, o objetivo deste trabalho é investigar as concepções de formadores de professores de Química sobre as possibilidades e potenciais dificuldades para ensinar conceitos químicos para licenciandos com deficiências.

\section{Revisão da literatura}

A inserção de alunos com necessidades educacionais especiais nas escolas pode trazer benefícios para todos os envolvidos, assim alunos podem aprender a conviver com as diferenças e alunos com necessidades educacionais especiais serão estimulados a se desenvolverem. Mas para que 
isso ocorra de forma efetiva a escola regular deve proporcionar recursos para atender às necessidades de todos os alunos.

\section{i) A inclusão no ensino superior}

Uma educação de qualidade é um direito garantido a todo cidadão, desde a infância até a fase adulta e é de responsabilidade do estado garantir que todos tenham acesso ao ensino sem distinção de cor, raça, etnia, diferenças sociais e físicas (BRASIL, 2012). Entretanto, muitos desafios surgem ao professor que se depara com algumas dessas diferenças. Por isso, a educação para alunos com necessidades educacionais especiais ganhou destaque sendo alvo de vários estudos científicos (SANTANA; FERNANDES, 2014).

Inicialmente, estas pesquisas focavam na educação básica, mais especificamente no ensino fundamental. Atualmente, em função da inserção das pessoas com necessidades especiais num mercado de trabalho cada vez mais competitivo, elas passaram a buscar sua qualificação profissional ingressando em cursos superiores (OMOTE, 2016). Com isso, amplia-se a preocupação com a formação destes alunos também no ensino superior, com a possibilidade de contratação de intérpretes de Libras, recursos didáticos adaptados, materiais em braile, além das adequações em relação ao acesso para deficientes físicos, com rampas e elevadores (OMOTE, 2016).

Entretanto, Rocha e Miranda (2009, p. 32) afirmam que não bastam criar leis e normas para garantir a permanência desses estudantes, "é preciso políticas públicas dirigidas com investimentos na qualificação de professores, e recursos tecnológicos, além da assistência estudantil nas universidades públicas em especial". Além disso, o estudante com deficiência, quando formado, precisa estar apto "para concorrer no mercado de trabalho em condição de igualdade com qualquer pessoa com a mesma formação" (OMOTE, 2016, p. 211). Por isso, o professor universitário precisa ser sensível para identificar quaisquer fatores contrários no aprendizado desse aluno, sabendo lidar com as diferenças e impedindo quaisquer preconceitos que possam surgir. 
Neste sentido, as instituições de ensino superior devem promover a sensibilização das unidades acadêmicas, dos professores e dos técnicos administrativos, ampliando a interação entre os alunos com necessidades educacionais especiais e a comunidade acadêmica (ROCHA; MIRANDA, 2009). Além disso, Vilela-Ribeiro e Benite (2010) alertam sobre a necessidade dos professores formadores estarem preparados para ensinar com inclusão e como isso afeta à formação dos professores na formação inicial: "os professores formadores devem ser os primeiros a se prepararem, com vistas a que só serão formados profissionais aptos para inclusão se os próprios formadores tiverem percepção sobre o assunto" (p. 588), compreendendo as necessidades destes estudantes, reorganizando os currículos e redefinindo os conceitos.

Nesta perspectiva, algumas pesquisas têm sido realizadas buscando compreender a inclusão de alunos com necessidades educacionais especiais no ensino superior. Gonçalves e colaboradores (2013) analisam uma proposta de abordagem de ensino de Química para cegos na formação de professores e o desenvolvimento de uma atividade experimental decorrente do referido processo formativo. Reis, Eufrásio e Bazon (2010) analisaram os conhecimentos teóricos e práticos sobre a deficiência visual de professores do ensino superior do curso de licenciatura em Ciências Biológicas. Já Ribeiro (2011) verificou que os professores de Biologia, Física, Matemática e Química não se sentem preparados para atuar e nem para formar para a diversidade. Melo (2013) analisou o ingresso e a permanência de educandos que apresentam deficiências, altas habilidades e transtornos globais do desenvolvimento, entre outras condições, em instituições de ensino superior.

\section{ii) A Química e a inclusão}

A Química é uma ciência que estuda as transformações envolvidas na matéria e tem inúmeras aplicações em setores relacionados ao funcionamento e ao desenvolvimento do país, e está presente no cotidiano. Por isso, "estudar Química no Ensino Médio ajuda o jovem a tornar-se mais bem informado, mais preparado para argumentar, para posicionar-se frente a questões e 
situações sociais que envolvem conhecimentos desta ciência” (BRASIL, 2016, p. 592). O conhecimento químico abre novos horizontes ao aluno, permitindoo uma melhor compreensão de diferentes fenômenos e uma maior consciência do seu cotidiano. Segundo Pereira e colaboradores (2009), conhecer Química é fundamental no mundo atual e pessoas com necessidades educacionais especiais não podem ser excluídas desse conhecimento. Por isso, é imprescindível o acesso a uma educação em Química de qualidade não só para formação cientifica, mas também para uma formação social. Sem o acesso às representações e as descrições que a Química oferece o aluno com deficiência passa a ser excluído do processo de ensino e aprendizagem (BRASIL, 2011a).

Como os demais alunos, aqueles que apresentam alguma necessidade educacional especial devem ter acesso a todos os níveis de estudo da Química. Sendo assim, é necessário promover adaptações que permitam acesso a esses conhecimentos, exigindo do professor um empenho complementar, buscando incansavelmente opções que promovam essa possibilidade, bem como da escola na qual os alunos estão inseridos (BRASIL, 2011a).

No processo de formação docente é de suma importância uma educação voltada a teorias de ensino-aprendizagem, mas também é importante e essencial a preparação de um professor que possa lidar com a desigualdade, como a discriminação, dificuldades de aprendizagem e vários outros aspectos que podem tomar uma sala de aula (OLIVEIRA; LACERDA, 2016). Neste sentido, alguns pesquisadores têm produzido trabalhos com o objetivo de orientar a inclusão de alunos com deficiência necessidade educacionais especiais nas aulas de Química. Alguns avaliam as dificuldades encontradas por professores, como Vilela-Ribeiro e Benite (2010) e Radmann e Pastoriza (2016); outros, como Retondo e Silva (2008) e Barbosa e Pacheco (2014), apresentam orientações e metodologias de ensino a fim de facilitar a aprendizagem dos conteúdos químicos em sala de aula.

\section{Metodologia}


A investigação é de natureza qualitativa, por enfatizar mais à compreensão do processo do que o produto (LÜDKE; ANDRÉ, 1986), por investigar a concepção dos formadores de professores de Química sobre a inclusão nas aulas. As entrevistas do tipo semiestruturadas foram realizadas com sete professores de uma instituição de Ensino Superior. As questões foram pensadas de forma a abranger a possibilidade de alunos com diferentes necessidades especiais ingressarem no curso de Química, a fim de levar os professores entrevistados a refletirem sobre suas metodologias, as necessidades de adaptação, assim como as possíveis dificuldades em lidar com esses alunos em sala de aula.

As questões foram elaboradas de forma a permitir que os entrevistados relatassem suas experiências, bem como suas impressões sobre o tema em questão. O critério para seleção dos sujeitos foi o fato de lecionar em curso de licenciatura em Química, buscando contemplar docentes de todas as áreas da Química, a saber: Ensino de Química, Físico-Química, Química Analítica, Química Inorgânica e Química Orgânica.

A escolha da entrevista, como instrumento para coleta de dados possibilita ao pesquisador, segundo Duarte (2004, p. 215), obter "indícios dos modos como cada um daqueles sujeitos percebe e significa sua realidade" e levantar informações sobre "a lógica que preside as relações que se estabelecem no interior daquele grupo”. Assim, as entrevistas realizadas com os professores foram semiestruturadas, pois partiram de alguns questionamentos que puderam ser ampliados à medida que novas questões surgiam a partir das respostas dos professores, elucidando assuntos que não tinham ficado claros ou recompondo o contexto da entrevista (BONI; QUARESMA, 2005). As entrevistas foram registradas em gravadores digitais de voz, com a permissão de todos os entrevistados, que assinaram termo de consentimento. As perguntas e respostas da entrevista semiestruturada foram transcritas na íntegra e analisadas sob a perspectiva da ATD (Análise Textual Discursiva). Foi assegurado a todos os sujeitos da pesquisa a garantia 
do anonimato; assim, durante as análises das respostas, foram atribuídos símbolos P1, P2, P3... no lugar dos nomes dos professores.

Após a análise das entrevistas, iniciou-se a definição das categorias descritivas, a partir das ideias e expressões semelhantes entre as respostas ou ainda aspectos relacionados, constituindo unidades a partir dos "enunciados referentes aos fenômenos estudados" (MORAES; GALIAZZI, 2011, p. 11). Na sequência, buscou-se o cruzamento das categorias com referenciais teóricos sobre os processos de ensino e aprendizagem de alunos com necessidades especiais em aulas de Química - o que será apresentado a seguir.

\section{Resultados e discussão}

Ao serem analisadas as respostas dos sete professores do curso de licenciatura em Química, nota-se a preocupação que estes demonstram sobre a inclusão de alunos com necessidades especiais em suas aulas. Além disso, percebe-se que a entrevista semiestruturada potencializou aos professores momentos de reflexão sobre a temática, uma vez que estes não se sentem preparados para receberem alunos com deficiências nas aulas de Química, até mesmo por desconhecer os processos de aprendizagem para eles ou não ter acesso a metodologias adequadas. Para a análise dos dados coletados durante as entrevistas, foram consideradas quatro categorias: i) impressões dos professores sobre a inclusão, ii) as aulas experimentais, iii) dificuldades na inclusão de deficientes auditivos e, iv) dificuldades na inclusão de deficientes visuais.

\section{i) Impressões dos professores sobre necessidades educacionais especiais}

Primeiramente os professores foram questionados sobre a possibilidade de ingresso de alunos com necessidades especiais no curso. Quatro professores afirmam que é possível o ingresso de alunos com necessidades especiais no 
curso de Química e três professores concordaram parcialmente. Os professores P5 e P7 também afirmaram pensar na possibilidade de inclusão nas aulas de Química, mas não justificaram ou aprofundaram tal posicionamento. Apesar de afirmarem ser possível o ingresso de alunos com necessidades especiais no curso de Química, quatro dos professores entrevistados acreditam que a instituição não está preparada ou que os docentes não possuem formação específica para receber esses alunos, como relatado nas falas: (P5): "Nosso curso não está preparado para receber alunos especiais" e (P1): "Nosso curso por enquanto não está preparado [...] Na verdade, eu acho que nenhum dos professores está preparado para isso".

O professor P1 acredita que não só o curso não está preparado, assim como os demais professores não teriam formação adequada para o trabalho com a educação especial nas aulas de Química. Outra preocupação para P7, em relação aos alunos inclusos, é a permanência dos mesmos na graduação, já que eles poderiam encontrar dificuldades durante seu processo de formação: (P7): "É a gente conseguir dar o suporte que ele realmente precise, conseguir fazer com que ele consiga superar as disciplinas, os componentes com as especificidades que ele exige".

Os professores entrevistados demonstraram preocupados no que diz respeito às aulas: (P6): "embora a gente precisasse trabalhar na ideia de uma formação um pouco mais específica para isso... acho que é possível desde que a gente saiba buscar formas para essa inclusão ocorrer realmente”. Neste caso, os professores desconsideram ou talvez não conheçam a possibilidade de parceria com centros de apoio à inclusão, que já existem na maior parte das instituições de ensino superior, sendo um espaço de atendimento e promoção de pessoas com necessidades educacionais especiais. Neste sentido, a Secretaria de Educação Especial aponta a necessidade da "constituição de uma equipe interdisciplinar, que permita pensar o trabalho educativo desde os diversos campos do conhecimento, é fundamental para compor uma prática inclusiva junto ao professor" (BRASIL, 2005b, p. 9). 
Quando levado a refletir na possibilidade de trabalhar conceitos químicos com alunos com necessidade educacional especial, P2 afirmou que seria um desafio, apesar de concordar com os outros professores sobre a falta de preparação do curso: (P2): "Para mim seria o mais difícil de conseguir contornar, mas eu ficaria feliz de ter esse tipo de desafio nas minhas turmas, embora o curso não esteja adaptado e apto a recebê-los”. Já os professores P1, P3 e P4 afirmaram nunca ter pensado em tal possibilidade de ter alunos com alguma necessidade especial em suas aulas: (P3): "Acho que nem na minha formação inicial pensei nessa possibilidade". Isso demonstra a necessidade de as instituições de ensino superior incluírem na preparação de futuros professores questões sobre a problemática da inclusão de alunos com necessidades educacionais especiais. Percebe-se em falas como esta que a possibilidade de inclusão causa insegurança para estes professores. Dessa forma, "para haver uma implantação real de práticas inclusivas nas Universidades é preciso repensar a preparação de seus professores, de maneira que eles conheçam o assunto e saibam se posicionar crítica e reflexivamente no ensino" (RIBEIRO, 2011, p. 59).

\section{ii) Aulas experimentais para alunos com necessidades educacionais especiais}

Mesmo não sendo foco da entrevista, todos os professores comentaram sobre as dificuldades que teriam em relação à inclusão nas aulas experimentais. Como os professores entrevistados são de um curso de Química, que tem um currículo em boa parte constituído por atividades experimentais, que são "instrumento de explicitação de teorias; de enculturamento no discurso científico, que inclui aprender as teorias estabelecidas pela ciência e aprender como se constrói o conhecimento científico" (GALIAZZI; GONÇALVES, 2004, p. 331). Os professores entrevistados mencionaram dificuldades que poderiam surgir aulas práticas principalmente no que diz respeito a alunos com deficiência visual, como destacam os professores: (P7): "como seria uma aula de titulação para um 
aluno cego?" e (P1): “O que eu fico com mais temor realmente é o visual, o restante eu ainda conseguiria dar um jeito de adaptar".

A experimentação no ensino de Química é marcada pelos sentidos visuais. Por exemplo, para caracterizar e evidenciar a ocorrência de fenômenos químicos, são utilizados aspectos estritamente visuais como a mudança de cor, a liberação de luz, a formação de precipitado ou o processo de liberação de gás. Para Santos e colaboradores (2015), as aulas experimentais de Química ainda são um desafio para a inclusão de deficientes visuais, pois os instrumentos presentes em laboratórios são desenvolvidos com escalas de medidas visuais e, portanto, impossíveis de serem utilizados por alunos que possuem deficiência visual.

Medições simples como determinação de massa ou de volumes se tornam inviáveis para um aluno com necessidades visuais, pois são procedimentos que exigem esse sentido e são comumente necessários em praticamente todos os experimentos da graduação. Entretanto, precisa-se avaliar a necessidade do aluno com deficiência visual em realizar tais procedimentos, já que a inclusão de alunos com necessidades especiais, "implica na flexibilização ou adequação do currículo, com modificação das formas de ensinar, avaliar, trabalhar com grupos em sala de aula" (BRASIL, 2005b, p. 27)

Verifica-se a necessidade de adaptação dos roteiros experimentais estimulando o estudante a utilizar o tato ou audição. É muito importante que o professor esteja atento quanto à escrita do roteiro, substituindo palavras como observar ou verificar, por sentir ou perceber, já que o aluno usará sentidos diferentes da visão. Sendo assim, há relatos de algumas experiências em Química adaptadas para deficientes visuais como Santos e colaboradores (2015) e Fernandes, Hussein e Domingues (2017). Outro aspecto elencado por todos os professores entrevistados, foi a questão da inclusão de alunos com dificuldades locomotoras para o acesso e a permanência no laboratório, nas aulas experimentais, como destaca (P5): "Nosso laboratório não tem acessibilidade, e aí seria um constrangimento para o aluno ter que sair da cadeira, ser levado nos braços por alguém até o laboratório”. Neste caso, é 
necessário investimento por parte da instituição superior e não só de adaptações do trabalho ou das metodologias dos professores. Afinal, é garantida em lei a acessibilidade aos estudantes e demais sujeitos da escola aos ambientes e atividades relacionadas a todas as etapas e níveis de ensino (BRASIL, 2015, p. 10).

\section{iii) Dificuldades na inclusão de deficientes auditivos}

$\mathrm{O}$ aluno com deficiência auditiva, bem como o deficiente visual, pode aprender Química utilizando os outros sentidos, já que a dificuldade que esses alunos encontram é com a comunicação. A legislação brasileira considera como "pessoa surda aquela que, por ter perda auditiva, compreende e interage com o mundo por meio de experiências visuais, manifestando sua cultura principalmente pelo uso da Libras" (BRASIL, 2005a, p. 28). Assim, a necessidade de inclusão da Libras como disciplina obrigatória nos currículos dos cursos de formação docente. Neste sentido, Sousa e Silveira (2011, p. 38) afirmam que o objetivo dessa lei é possibilitar a formação de "professores mais bem preparados em suas áreas específicas de formação e, ainda, com conhecimentos para lidar com a Libras". Entretanto, pelo que pode ser observado nas falas que serão descritas a seguir, os professores do curso de Licenciatura em Química, participantes da pesquisa, não se sentem preparados para ensinar utilizando Libras.

Os professores apontaram algumas dificuldades que poderiam enfrentar, destacando que o principal obstáculo seria a comunicação com os alunos, já que eles afirmaram não saber Libras, como destaca (P2): "haveria dificuldades para trabalhar os conceitos químicos, porque é como se falasse com alguém que fala inglês". A comunicação seria prejudicada já que para o surdo, a Libras é sua primeira língua e essa seria uma das dificuldades para lidar com esses alunos em uma sala de aula.

Os professores sentem necessidades de uma formação mais voltada para esse tipo de deficiência. Pois, como afirmam os professores P1, P2 e P3 nenhum docente da instituição conhece Libras. Sousa e Silveira (2011) 
apontam que é necessária uma capacitação dos professores para trabalharem com deficientes auditivos, para que eles não se distanciem das aulas por não compreenderem os conceitos químicos, o que "gera exclusão e distanciamento dos alunos surdos nas aulas desse conteúdo" (p. 38). Segundo os professores, uma solução que poderia minimizar as dificuldades seria um intérprete de Libras para ser o mediador entre o docente e o aluno: (P5): "A gente vai precisar de tradutor ou intérprete e no caso específico de problemas com audição e hoje a gente não tem”.

Mas há um ponto negativo levantado sobre o intérprete de Libras, como a Química possui símbolos e linguagem própria, os docentes não se sentem confiantes se aquilo que falam está sendo fielmente interpretado para o aluno por meio do intérprete como apontam P3 e P5: (P3): “A comunicação seria difícil, assumindo que exista uma pessoa fazendo a tradução, não teria como eu confirmar se o que estou falando realmente é o que está sendo traduzido" e (P5): “A universidade até disponibiliza interprete, mas normalmente não é alguém com conhecimento de química, então tem palavras que são difíceis para a interpretação... acho que é mais complexa para o aluno entender". Algumas linguagens e termos químicos específicos - átomo, elétron, mol, íon, próton, dentre outros, que não compõem a ementa de terminologias dos dicionários de Libras, pode ser um meio que dificulte a construção de sentidos dos conceitos químicos (SOUSA; SILVEIRA, 2011). (P3): "Não imagino como seria dizer por exemplo ácido sulfúrico em língua de sinais". Outro apontamento feito por P5 seria sua postura diante da sala. Ele acredita que isso seria uma dificuldade, já que algumas pessoas com deficiência auditiva conseguem fazer leitura labial. Então durante sua aula o professor deve estar atento em sempre falar de frente para o aluno.

É imprescindível que o docente tenha essa sensibilidade para se atentar a esses detalhes que, talvez, passe despercebido para um professor que possua apenas alunos ouvintes, pois segundo Pereira, Benite e Benite (2011, p. 38), "a cultura surda é multifacetada, porém apresenta característica específica: ela é visual, ela se traduz de forma visual e o impacto dessa singularidade é 
muito significativo". Além disso, estes autores afirmam que a confusão dos conceitos e a exigência de um nível maior de raciocínio se deve à ausência de material de apoio para estudo como fatores determinantes das dificuldades no aprendizado da Química.

\section{iv) Dificuldades na inclusão de deficientes visuais}

Deparar-se com alunos que possuem deficiência visual é uma preocupação constante para professores de Química, considerada como uma ciência visual, muitos professores sentem dificuldades ou não veem formas de se trabalhar satisfatoriamente com esses alunos: (P3): "As dificuldades seriam todas as possíveis e imagináveis, acho que não estou capacitado para dar aula para um aluno com deficiência visual" e, (P4): "Uma coisa que sempre parei para pensar na questão da pessoa com deficiência visual, com dificuldade de visualizar”. Isso demonstra que os professores não se sentem confiantes em ter um aluno com deficiência visual em suas turmas e que a formação de professores tem dado pouca atenção à chamada educação inclusiva, de modo geral, e à educação para deficientes visuais, em particular (GONÇALVES et al., 2013).

Atualmente, pesquisas e materiais têm sido desenvolvidos a fim de orientar e auxiliar educadores em aulas para alunos cegos ou com baixa visão (PIRES, MÓL, RAPOSO, 2007; GONÇALVES, et al., 2013; SANTOS, et al., 2015). É possível encontrar novas maneiras e possibilidades para elaboração de aulas, mas infelizmente muitos professores desconhecem tais materiais, como afirma o professor (P5): "Seria bom ter um material em braile ou a proposição de nomenclatura química em linguagem de sinais, para usar nas aulas de Química, mas não sei se alguém já pensou nisso”. Já P6 e P7 sentem a necessidade de adaptação dos materiais acessíveis para que o aluno possa acompanhar as aulas que serão ministradas. No entanto, há no ensino de química, a produção de um manual de grafia química braile (BRASIL, 2011a) para ser explorado no sistema educacional brasileiro. Esse documento contribui de forma singular para atender à demanda crescente de estudantes 
cegos e com baixa visão no ensino médio, mas seria muito importante para o ensino superior.

Mesmo que pareça uma tarefa árdua e desafiadora, o professor precisa buscar subsídios na intenção de incentivar o Ensino de Química para deficientes visuais, com o intuito de que se tornem profissionais capazes, como quaisquer outros indivíduos com necessidades diferentes. Gonçalves e colaboradores (2013, p. 266) afirmam que a natureza do curso de Química e a especificidade do seu conjunto de conhecimentos de caráter procedimental "parece ser um desafio a mais para os docentes na promoção de um processo de ensino e aprendizagem para alunos deficientes visuais”. Mas completam que tais dificuldades "não podem absolutamente servir como critérios de exclusão de tais alunos. Cabe aos professores encontrar soluções para que os deficientes visuais também possam ser profissionais que trabalhem com ciência”. (GONÇALVES et al., 2013, p. 266)

Ainda, segundo estes autores, existem publicações que se destinam, entre outros aspectos, a divulgar metodologias, como o uso de ferramentas tecnológicas, para os professores e que podem favorecer o processo de ensino e aprendizagem para os estudantes com deficiência visual. Dessa forma, professores poderão adotar práticas inclusivas quando forem adequadamente preparados para tal, utilizando recursos pedagógicos próprios para cada necessidade individual.

\section{Conclusão}

A inclusão de alunos com necessidades educacionais especiais no ensino superior visa equalizar as oportunidades sociais destas pessoas, mas se mostra como um grande desafio para os professores universitários. Ela ocorre de forma lenta e com escassos mecanismos que sustentem o acesso e, principalmente a permanência dos alunos no curso de graduação. Não se trata apenas de garantir vagas, mas da organização de estratégias que 
garantam o sucesso desse aluno com necessidades educacionais especiais (MELO, 2013).

A pesquisa demonstrou que os professores de Química se sentem inseguros e se dizem despreparados para ensinar alunos com algum tipo de deficiência, especialmente, alunos com deficiência visual. Já que as aulas de Química privilegiam sobremaneira a visualização de modelos, fórmulas, equações, gráficos e, em especial nas aulas experimentais, por exemplo, para evidenciar a ocorrência de uma reação química verifica-se a mudança na cor, a formação de precipitado, a liberação de gases... todas as evidências que exigem a visualização. Entretanto, na literatura verificamos inúmeras possibilidades de adaptações de materiais acessíveis aos educadores, que se usados de forma adequada, podem auxiliar nas aulas de Química.

Para a constituição de uma instituição que atenda as diferenças de todos os alunos compreende-se a urgência de articulação das ações visando efetivar a inserção dos alunos com necessidades educacionais especiais. Isso implica do professor precisa desenvolver processos de reflexão na e pela prática em sala de aula, reorganizando suas estratégias de ensino-aprendizagem de forma a abranger todos os alunos em uma mesma atividade. Compreende-se que as concepções dos formadores de professores acerca da inclusão influenciam também as concepções dos futuros professores de Química. Por isso, a importância destes professores repensarem suas práticas a fim de influenciar na formação e atuação profissional dos licenciandos, enquanto futuros professores de Química na educação básica.

Entendemos também que a inclusão não é responsabilidade apenas do professor, mas também da instituição de ensino que deve fornecer subsídios tanto para os alunos, quanto para os docentes e técnicos administrativos, para que todos possam participar de forma ativa e efetiva do ensino superior, buscando o sucesso profissional e ascensão social. Para isso, é importante que as instituições de ensino superior ofereçam cursos de formação não apenas para os professores, mas aos demais alunos e servidores, que convivem com as pessoas com necessidades especiais no ambiente acadêmico. Por isso, se faz 
necessário maiores investimentos na área da educação especial, pois assim possibilitará na melhoria da qualidade de ensino, resultará no fortalecimento profissional de futuros professores de Química que possuem algum tipo de deficiência.

\section{Referências}

BARBOSA, K. C. M.; PACHECO, D. Química e surdez: novas propostas no processo de ensino. In: Anais do IV Simpósio Nacional de Ensino de Ciências e Tecnologia. Ponta Grossa-PR, p. 1-12, 2014.

BONI, V.; QUARESMA, S. J. Aprendendo a entrevista: como fazer entrevistas em ciências sociais. Revista Eletrônica dos Pós-Graduandos em Sociologia Política da UFSC, v. 2, n. 1 (3), p. 68-80, 2005.

BRASIL, Casa Civil, Lei n. 13.146, de 6 de julho de 2015. Institui a Lei brasileira de inclusão da pessoa com deficiência. Brasília: Diário Oficial, 2015.

- Constituição da República Federativa do Brasil: texto constitucional promulgado em 5 de outubro de 1988, 35ª ed. Brasília: Câmara dos Deputados, 2012.

Ministério da Educação, Decreto n. 5.626, de 22 de dezembro de 2005 - que dispõe sobre a Língua Brasileira de Sinais - Libras. Brasília: Diário Oficial da União, p. 28,2005 a.

Base nacional comum curricular: Proposta preliminar. 2a versão revista. Brasília, 2016.

. Secretaria de Educação Continuada, Alfabetização, Diversidade e Inclusão.

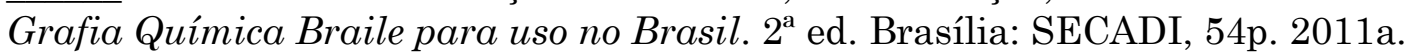

Secretaria de Educação Especial. Documento subsidiário à política de inclusão. 48f. Brasília: MEC, 2005b.

Lei n. 9394/96 - Lei de Diretrizes e Bases da Educação Nacional, Diário Oficial da União, p. 27833, 1996.

Ministério das Relações Exteriores. Decreto n. 3.956. de 8 de outubro de 2001 - Convenção Interamericana para eliminação de todas as formas de discriminação contra as pessoas portadoras de deficiência. Diário Oficial da União, p. 1, 2001.

. Secretaria de Direitos Humanos. Convenção sobre os direitos das pessoas com deficiência. Brasília: SDH, 100f., $2011 b$. 
CAMARGO, E. P.; NARDI, R. Planejamento de atividades de ensino de Física para alunos com deficiência visual: dificuldades e alternativas. Revista Electrónica de Enseñanza de las Ciencias, v. 6, n. 2, p. 378-401, 2007.

DUARTE, R. Entrevistas em pesquisas qualitativas. Educar, n. 24, p. 213-255, 2004.

FERNANDES, T. C.; HUSSEIN, F. R. G. S.; DOMINGUES, R.C. P. R. Ensino de química para deficientes visuais: a importância da experimentação num enfoque multissensorial. Química Nova na Escola, v. 39, n. 2, p. 195-203, 2017.

GALIAZZI, M. C.; GONÇALVES, F. P. A natureza pedagógica da experimentação: uma pesquisa na licenciatura em Química. Química Nova, v. 27, n. 2, p. 326-331, 2004.

GONÇALVES, F. P.; REGIANI, A. M.; AURAS, S. R.; SILVEIRA, T. S.; COELHO, J. C.; HOBMEIR, A. K. T. A educação inclusiva na formação de professores e no ensino de Química: a deficiência visual em debate. Química Nova na Escola, v. 35, n. 4 , p. 264-271, 2013.

LÜDKE, M.; ANDRÉ, M. E. D. A. Pesquisa em educação: abordagens qualitativas. São Paulo: EPU, 1986.

MELO, F. R. L. V. (org.) Inclusão no ensino superior: docência e necessidades educacionais especiais. Natal: EDUFRN, 2013.

MORAES, R.; GALIAZZI, M. C. Análise textual discursiva. 2.ed. Ijuí: Unijuí. 2011.

OLIVEIRA, B. T.; LACERDA, N. O. S. Educação inclusiva: análise da legislação dos portadores de deficiência na educação do Brasil. In: Anais do III Congresso de Ensino, Pesquisa e Extensão da UEG, Pirenópolis-GO, p. 1-7, 2016.

OMOTE, S. Atitudes em relação à inclusão no ensino superior. Journal of Research in Special Educational Needs, v. 16, n. 1, p. 211-215, 2016.

PACHECO, R. V.; COSTAS, F. A. T. O processo de inclusão de acadêmicos com necessidades educacionais especiais na Universidade Federal de Santa Maria. Revista Educação Especial, n. 27, p. 151-167, 2006.

PEREIRA, F.; SOUSA, J. A.; MATA, P.; LOBO, A. M. Desenvolvimentos no ensino da Química a cegos e a grandes amblíopes. Boletim da Sociedade Portuguesa de Química, série II, n. 112, p. 7-15, 2009.

PEREIRA, L. L. S.; BENITE, C. R. M.; BENITE, A. M. C. Aula de Química e surdez: sobre interações pedagógicas mediadas pela visão. Química Nova na Escola, v. 33, n. 1, p. 47-56, 2011.

PIRES, R. F. M.; RAPOSO, P. N.; MÓL, G. S. Adaptação de um livro didático de Química para alunos com deficiência visual. In: Anais do VI Encontro Nacional de Pesquisa em Educação em Ciências, Florianópolis: 2007 
RADMANN, T.; PASTORIZA, B. S. Educação Inclusiva no ensino de Química. In: Anais do XVIII Encontro Nacional de Ensino de Química (XVIII ENEQ), Florianópolis-SC, 2016.

REIS, M. X.; EUFRÁSIO, D. A.; BAZON, F. V. A formação do professor para o ensino superior: prática docente com alunos com deficiência visual. Educação em Revista, v. 26, n. 1, p.111-130, 2010.

RETONDO, C. G.; SILVA, G. M. Ressignificando a formação de professores de Química para a educação especial e inclusiva: uma história de parcerias. Química Nova na Escola, n. 30, p. 27-33, 2008.

RIBEIRO, E. B. V. Formação de professores de ciências e educação inclusiva em uma instituição de ensino superior em Jataí-GO. Dissertação (Mestrado em Educação em Ciências e Matemática). Universidade Federal de Goiás. 107f. 2011.

ROCHA, T. B.; MIRANDA, T. G. A inclusão de alunos com deficiência no ensino superior: uma análise de seu acesso e permanência. In: DÍAZ, F., BORDAS, M.; GALVÃO, N.; MIRANDA, T. (org.). Educação inclusiva, deficiência e contexto social: questões contemporâneas [online]. Salvador: EDUFBA, p. 27-37, 2009.

SANTANA, M. Z.; FERNANDES, P. Políticas de educação inclusiva no Brasil: uma reflexão acerca da inclusão do estudante com necessidades educativas especiais no ensino superior a partir da legislação. In: Anais do I Seminário Internacional em Direitos Humanos e Escola Inclusiva: construindo boas práticas. Portugal/Algarve, p. 278-290, 2014.

SANTOS, S. R. B.; DANIEL, L. X. L.; SILVA, A. A.; SILVA, P. R. A.; MEDEIROS, E. A. S.; SANTOS, L. M. Química experimental para deficientes visuais. Latin American Journal of Science Education, 2, 12015, p.1-7, 2015.

SOUSA, S. F.; SILVEIRA, H. E. Terminologias químicas em Libras: a utilização de sinais na aprendizagem de alunos surdos. Química Nova na Escola, v. 33, n. 1, p. 37 46, 2011.

VILELA-RIBEIRO, E. B.; BENITE, A. M. C. A educação inclusiva na percepção dos professores de Química. Ciência \& Educação, v. 16, n. 3, p. 585-594, 2010. 